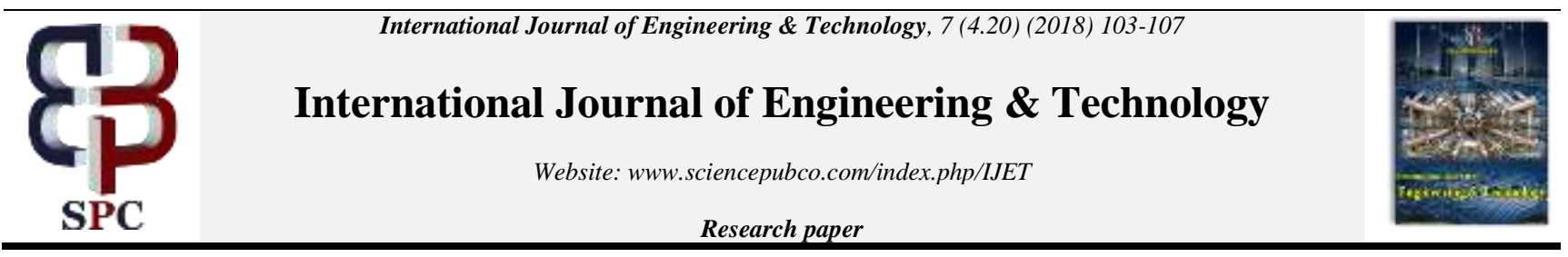

\title{
Enhancement of the Ductility Index of Concrete Pavement Using Moderate-Volume of Hybrid Fibers
}

\author{
Qais Sahib Banyhussan \\ Department of Highway and Transportation Engineering, Faculty of Engineering, Mustansiriyah University, Baghdad, Iraq \\ *Corresponding author E-mail :qaisbanyhussan@gmail.com
}

\begin{abstract}
The concrete used in highway structures such as pavements, bridge approach slabs or bridge decks are deteriorated much faster rate than other concrete structures due to environmental and traffic loads leading to sudden failure and/or more cracking potential. The present paper investigates experimentally the development of ductile concrete mixtures. Twenty-four mixtures with three types of fibers (PVA, Hocked steel fiber and Nylo-mono) were used. River sand as a fine aggregate and coarse aggregate with a maximum aggregate size of $(9.5 \mathrm{~mm})$ were adopted. Fly ash was used as a replacement of Portland cement with three ratios. Compressive and flexural strengths tests were achieved at different curing ages (7,28 and 90 days) to determine the stress and ductility indexes. The results show that due to more fly ash content there is an increase in the stress index and decrease in the ductility index for mixtures containing $1 \%$ steel and $1 \%$ PVA fibers by volume. In addition, the results demonstrated that using of Nylo-mono enhances the ductility index better than PVA. Finally, the use of $2 \%$ by volume hybrid fiber (PVA0.5+Steel.0\%+Nylo-mono 0.5 ) achieved a ductile concrete mixture that has a ductility index nine times higher than that of plain concrete.
\end{abstract}

Keywords: Concrete pavement, deflection hardening, ductility index, hybrid fiber, stress index.

\section{Introduction}

The concrete used in highway structures; pavements, bridge approach slabs or bridge decks are deteriorated much faster than other concrete structures due to mainly environmental factors and traffic loads. This deterioration costs millions of US dollars annually for repair or maintenance. Preventing harmful agent to enter into the concrete by increasing a certain performance criterion like crack resistance, durability enhancement and post crack flexural stiffness is a way used to promote the service life of concrete. A Hybrid Fiber Reinforced Concretes (HyFRCs), for example, is developed for the use in highway structures.

High-Performance Fiber Reinforced Concrete Composite (HPFRCC) is a new type of developed concrete. Its demeanor after the first crack is a quasi-deflection-hardening response, which mostly appears as a multiple cracks and energy absorption capacity. The main point of deflection-hardening response concrete is that the post cracking strength is more than the first cracking strength, or a ductile behavior.

High performance fiber reinforced cementitious composites are described by a comparatively high elastic limit, strain or deflection hardening and energy absorption related with multiple cracks mechanism [1]. When fiber reinforced cementitious composites are subjected to bending stress, the load-carrying capacity increases due to the increase in the post peak. However, the stiffness of cracked part could cause the stress of first crack point rises when the fiber fraction is sufficiently high. This response is known as deflection hardening behavior [2].

Fibers, especially hybrid fibers, when they are added into the concrete may improve the performance in hardening phase and make it with more strength, ductile and cracking resistance than fragile condition. Using two or more different fibers in concept of hybrid- ization combined cement matrix, could lead to more desirable engineering properties due to the presence of one fiber that enables more effective utilizations of the possible properties of the other fiber [3].

Fiber, matrix and fiber-matrix interfaces are the main ingredient of the composite material. To achieve a strain or deflection hardening response, a synergistic interaction between composite components should be taken into account. To ensure elastic-plastic behavior (i.e. ductile), the crack tip toughness Jtip (matrix fracture toughness) should be less than the complementary energy $\mathrm{J}_{\mathrm{b}}$,calculated from the fiber bridging stress $\left(\sigma_{\mathrm{B}}\right)$ vs crack opening $(\delta)$ curve, as shown in Figure 1 and illustrated in Equations 1and 2 below.

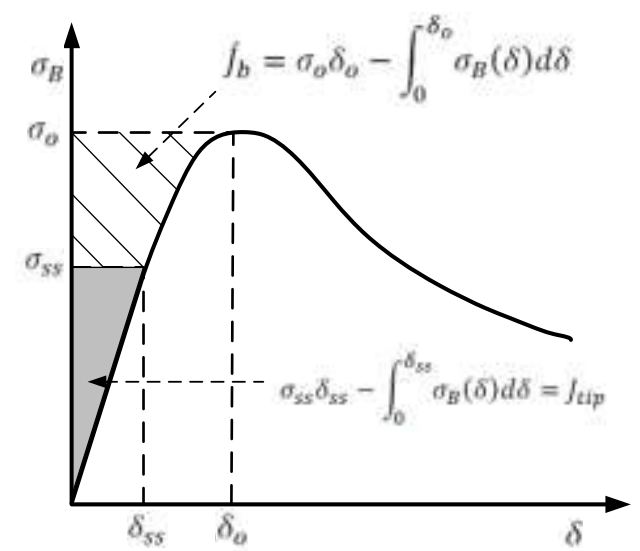

Fig. 1: Typical bridging stress vs crack opening curve for a tensile strainhardening composite. Hatched area represents complementary energy $\mathrm{J}_{\mathrm{b}}$. Shaded area represents crack tip toughness $\mathrm{J}_{\text {tip }}$ [4]. 
$\mathrm{J}_{\text {tip }} \leq \sigma_{\mathrm{U}} \delta_{\mathrm{U}}-\int_{0}^{\delta_{\mathrm{O}}} \sigma(\delta) \mathrm{d} \delta \equiv \mathrm{J}_{\mathrm{b}}^{\prime}$

$\mathrm{J}_{\mathrm{tip}}=\frac{\mathrm{K}_{\mathrm{m}}^{2}}{\mathrm{E}_{\mathrm{m}}}$

Generally, the volume ratio of fluid phase decreases with increases maximum aggregate size and its content. Therefore, the volume of space required for fiber decreases, which may lead to phenomenon of balling. Having said that, uniform dispersion of fiber becomes harder when aggregate size is increased [6]. The decrease in fiber distribution and orientation leads to decrease the fiber effectiveness for bridging the loads at cracks, which leads to reduce the ductility.

\section{Study purpose}

The brittleness of concrete is undesirable property, which may cause sudden failure or high cracking potential. The present study seeks for increasing the ductility index by changing the brittle behavior of concrete to ductile behavior by utilizing moderate volume of hybrid fiber with a high aggregate to binder (A/B) ratio of up to 2 .

\section{Experimental program}

\subsection{Materials and mixture proportions}

Type I Portland cement (C) was used in all batches. Two types of mineral admixtures; silica fume (SF) and class F fly ash (FA) were added as a cement replacement material. Table (1) shows the chemical composition and physical properties of the cementitious material. Chemical admixture, Superplasticizer (SP), was added to reduce the amount of water required to obtain the desired consistency of the mix. River sand as fine aggregates with a finesse modulus of (2.67), and coarse aggregates with $(9.5 \mathrm{~mm})$ maximum aggregate size were included.

Table 1: Chemical composition and physical properties of Portland cement, Class-F fly Ash and silica fume.

\begin{tabular}{llll}
\hline \hline Chenrical composition \% & PC & FA & SF \\
\hline $\mathrm{SiO} 2$ & 20.77 & 5.701 & 91.96 \\
$\mathrm{~A} 12 \mathrm{O} 3$ & 5.55 & 20.97 & 1.20 \\
$\mathrm{Fe} 2 \mathrm{O} 3$ & 3.35 & 4.15 & 0.84 \\
$\mathrm{M} g \mathrm{O}$ & 2.49 & 1.76 & 1.02 \\
$\mathrm{CaO}$ & 61.4 & 9.78 & 0.62 \\
$\mathrm{Na} 2 \mathrm{O}$ & 0.19 & 2.23 & 0.67 \\
$\mathrm{~K} 2 \mathrm{O}$ & 0.77 & 1.53 & 1.16 \\
Loss on Ignition (LOD) & 2.2 & 1.25 & 1.86 \\
Physical properties & & & \\
Specific gravity & 3.15 & 2.2 & 2.3 \\
Blaine fineness (mo/g) & 325 & 290 & - \\
\hline \hline
\end{tabular}

\subsection{Optimizing the aggregate gradations}

Bond glue is the constituent of solid that experiences the most shrinkage, while total gives limitation and points of confinement shrinkage. Consequently, solid blends containing a high volume of total (a low volume of bond glue) have both decreased shrinkage and breaking. An enhanced consolidated total degree enables the volume of total to be boosted while keeping up great plastic solid attributes. Notwithstanding lessened shrinkage and splitting potential with the decrease of glue substance, cements with very much reviewed totals display less isolation, increment cohesiveness and enhance usefulness contrasted with cements with poor joined degrees. In this work, changed 0.45 power graph was received to discover all around reviewed degree. Figure 2 demonstrates the sieving examination of total and its last mix that utilized in all groups contrasted and the degree furthest reaches of more full recipe. Fuller recipe used to get the hypothetical Greatest Thickness Bends degree as demonstrated as follows:

$\mathrm{P}=(\mathrm{d} / \mathrm{D})^{0.45}$

where:

$\mathrm{P}=\%$ passing sieve size $(\mathrm{d})$

$\mathrm{D}=$ maximum nominal aggregate size Water to cementitious materials $(\mathrm{PC}+\mathrm{FA})$ ratio $(\mathrm{W} / \mathrm{CM})$ and fly ash to Portland cement

Three different fibers by volume were used in this work: polyvinyl alcohol (PVA) fiber (length $=18 \mathrm{~mm}$, diameter $=0.4 \mathrm{~mm}$ ); hocked steel fiber $(\mathrm{S})$ (length $=30 \mathrm{~mm}$, diameter $=0.75 \mathrm{~mm}$ ) and Nylomono fiber $(\mathrm{N})$ (length $=19 \mathrm{~mm}$, diameter=0.05). Table 2 shows the properties of the fibers used.

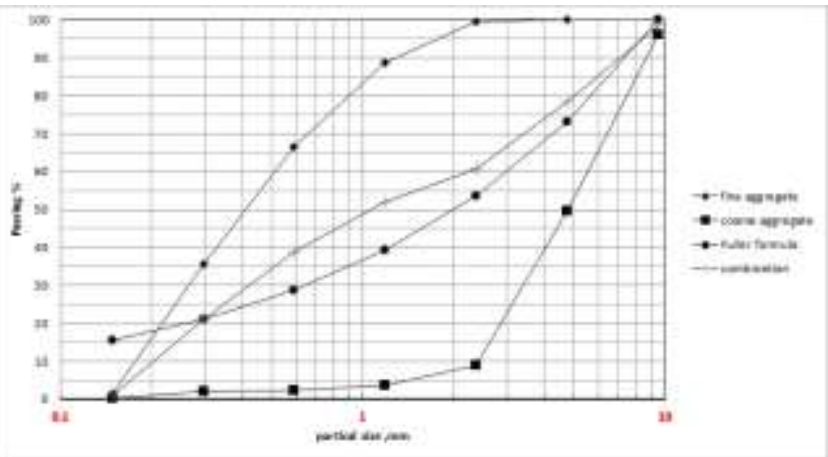

Fig. 2: Particle size distributions of fine aggregate, coarse aggregate and theoretical maximum density (Fuller formula).

Table 2: Properties of fibres.

\begin{tabular}{llllll} 
Table 2: Properties of fibres. \\
\hline Material & $\begin{array}{l}\text { Length } \\
(\mathrm{mm})\end{array}$ & $\begin{array}{l}\text { Diameter } \\
(\mathrm{mm})\end{array}$ & $\begin{array}{l}\text { Strength } \\
(\mathrm{Mpa})\end{array}$ & $\begin{array}{l}\text { Stiffness } \\
(\mathrm{Gpa})\end{array}$ & $\begin{array}{l}\text { Specific } \\
\text { Gravity }\end{array}$ \\
\hline PVA & 18 & 0.4 & 1000 & 29 & 1.3 \\
Steel & 30 & 0.75 & 1100 & 200 & 7.8 \\
Nylo- & 19 & 0.05 & 1000 & 25 & 1.14 \\
mono & & & & & \\
\hline
\end{tabular}

In total, 24 mixtures were manufactured in this study. Mixture proportions are given in Table 3 . A constant water to binder ratio $(\mathrm{w} / \mathrm{B}=0.4)$ are considered. Besides that, the fraction of silica fume, as a cement replacement by weight was adopted to be (0.07) To reduce the amount of cement, three ratios of fly ash to Portland cement $(\mathrm{FA} / \mathrm{C})(0.2,0.45$ and 0.7$)$ and three ratios of aggregate to binder (A/B) (1, 1.5 and 2) were utilized. One (fine aggregate/coarse aggregate) ratio (57/43) was selected to obtain a dense gradation closed to the Fuller maximum curve.

\subsection{Sample preparation and testing}

Concrete mixer pan type with 40 liters was used to prepare all batches. Firstly, fine aggregate and coarse aggregate are mixed dry for 3 minutes. After that, cement and fly ash have been added to the dry blended for 5 minutes. Silica fume and SP are mixed in the mixing water and then introduced gradually to the mixture at least 5 minutes until obtaining a desired consistency. Finally, the whole materials are additionally mixed for 5 minutes after inclusion of fibers.

Each mixture is casted into cubic molds with dimensions of $(100 \mathrm{~mm} \times 100 \mathrm{~mm} \times 100 \mathrm{~mm})$ for compression test and prisms with dimensions of $(80 \mathrm{~mm} \times 75 \mathrm{~mm} \times 400 \mathrm{~mm})(\mathrm{W} \times \mathrm{H} \times \mathrm{L})$ for bending test After 24 hours, all samples are demolded and kept in moisture plastic bags at $95+5 \% \mathrm{RH}, 23+2^{\circ} \mathrm{C}$ until the age of testing; 7,28 and 90 days. Specimen length of $350 \mathrm{~mm}$ with $116 \mathrm{~mm}$ a center span length was examined by four- point bending test to evaluate the flexural strength. At the same time, the mid-span deflection is recorded. The bending test was achieved on a closed-loop controlled-computerized system at a loading rate of $0.1 \mathrm{~mm} / \mathrm{s}$. In the stress-deflection curve, three values have been reported; first crack 
stress, flexural strength (modulus of rupture (MOR) which repre- $\quad$ sents the maximum stress and the deflection capacity.

Table 3: Mixture proportions.

\begin{tabular}{|c|c|c|c|c|c|c|c|c|}
\hline $\begin{array}{c}\text { Mix. } \\
\text { No. }\end{array}$ & Cement & FA/C & $\mathrm{SF} / \mathrm{C}$ & W/B & PVA & $\begin{array}{c}\text { Steel } \\
\text { Fiber }\end{array}$ & $\begin{array}{l}\text { Nylo- } \\
\text { Mono }\end{array}$ & $\mathbf{A} / \mathbf{B}$ \\
\hline 1 & 1 & 0.20 & 0.07 & 0.4 & 0.0 & 0 & 0.0 & 1.0 \\
\hline 2 & 1 & 0.45 & 0.07 & 0.4 & 0.0 & 0 & 0.0 & 1.0 \\
\hline 4 & 1 & 0.20 & 0.07 & 0.4 & 0.0 & 1 & 0.0 & 1.0 \\
\hline 5 & 1 & 0.45 & 0.07 & 0.4 & 0.0 & 1 & 0.0 & 1.0 \\
\hline 6 & 1 & 0.70 & 0.07 & 0.4 & 0.0 & 1 & 0.0 & 1.0 \\
\hline 7 & 1 & 0.20 & 0.07 & 0.4 & 1.0 & 1 & 0.0 & 1.0 \\
\hline 8 & 1 & 0.45 & 0.07 & 0.4 & 1.0 & 1 & 0.0 & 1.0 \\
\hline 9 & 1 & 0.70 & 0.07 & 0.4 & 1.0 & 1 & 0.0 & 1.0 \\
\hline 10 & 1 & 0.20 & 0.07 & 0.4 & 1.0 & 1 & 0.0 & 1.5 \\
\hline 11 & 1 & 0.45 & 0.07 & 0.4 & 1.0 & 1 & 0.0 & 1.5 \\
\hline 12 & 1 & 0.70 & 0.07 & 0.4 & 1.0 & 1 & 0.0 & 1.5 \\
\hline 13 & 1 & 0.20 & 0.07 & 0.4 & 1.0 & 1 & 0.0 & 2.0 \\
\hline 14 & 1 & 0.45 & 0.07 & 0.4 & 1.0 & 1 & 0.0 & 2.0 \\
\hline 15 & 1 & 0.70 & 0.07 & 0.4 & 1.0 & 1 & 0.0 & 2.0 \\
\hline 17 & 1 & 0.45 & 0.07 & 0.4 & 0.5 & 1 & 0.5 & 1.0 \\
\hline 18 & 1 & 0.70 & 0.07 & 0.4 & 0.5 & 1 & 0.5 & 1.0 \\
\hline 19 & 1 & 0.20 & 0.07 & 0.4 & 0.5 & 1 & 0.5 & 1.5 \\
\hline 20 & 1 & 0.45 & 0.07 & 0.4 & 0.5 & 1 & 0.5 & 1.5 \\
\hline 21 & 1 & 0.70 & 0.07 & 0.4 & 0.5 & 1 & 0.5 & 1.5 \\
\hline 22 & 1 & 0.20 & 0.07 & 0.4 & 0.5 & 1 & 0.5 & 2.0 \\
\hline 23 & 1 & 0.45 & 0.07 & 0.4 & 0.5 & 1 & 0.5 & 2.0 \\
\hline 24 & 1 & 0.70 & 0.07 & 0.4 & 0.5 & 1 & 0.5 & 2.0 \\
\hline
\end{tabular}

\section{Results and discussions}

\subsection{Compressive strength}

Figure 3 shows the compressive strength results of 24 mixtures. The results indicate that the increasing of FA replacement ratio causes a reduction in compressive strength at the same amount of fiber content and aggregate-binder $(\mathrm{A} / \mathrm{B})$ ratio. It may be attributed to the particle size of FA which is larger than the normal Portland cement. Thereby, FA has smaller surface area than cement which cause a slower hydrate in the presence of alkaline medium formed by the cement particles dissolution [7].

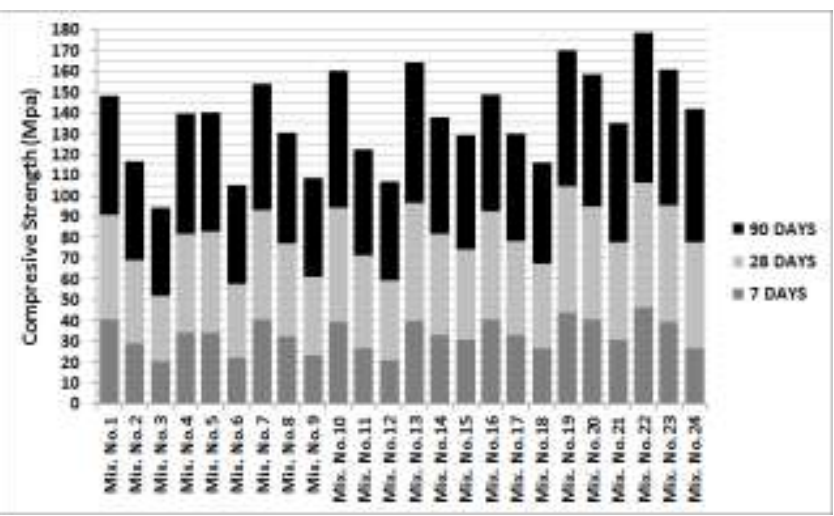

Fig. 3: Compressive strength at different ages.

\subsection{Flexural Stress and Load-Deflection Curve}

Results of average flexural strength and deflection capacity of four specimens of each mix tested at different ages are summarized in Figures 4 and 5 for maximum stress and maximum deflection, respectively.

Concrete without fibers (mix. No. 1-3) is brittle and has a lowest flexural strength. The curve went up till peak strength and then dropped down. The load-deflection curve of concrete with hocked steel fiber (Mix. No.4-6), although it has $1 \%$ fiber content by volume, displays a quasi-deflection-hardening response (i.e. more ductility index). It may be attributed to content of (SF) which in- creases the bond of fiber with concrete matrix and increases the performance represented by ductility of concrete [8]. Moreover, efficient fiber distribution and orientation improve the bridging of fiber to carry loads. In this study, visual inspection of fiber distribution was achieved by cutting the tested specimens after testing to see the steel fiber distribution and orientation, as shown in Plate 1 .

Addition of PVA fiber, (Mix. No. 8-15) with total fiber content (steel and PVA) of $2 \%$, contributes in increasing the flexural strength and deflection capacity. This improvement is due to the synergy between fibers added into concrete (steel and PVA).

Figure 6 and 7 illustrate the effect of addition of Nylo-mono fiber of $0.5 \%$ by volume instead of the same percentage of PVA fiber. For aggregate-binder $(\mathrm{A} / \mathrm{B})$ ratio $=1$, the addition of Nylo-mono fiber leads to lowering the deflection capacity and stated a reduction in flexural strength, respectively.

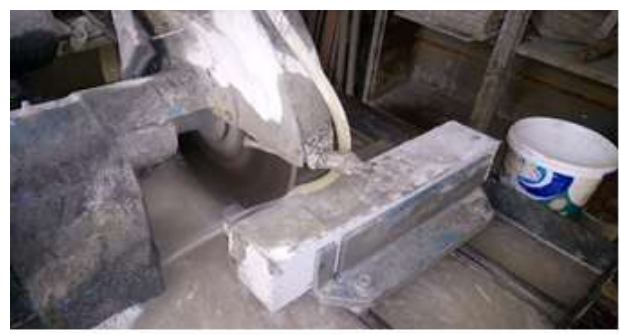

(a)

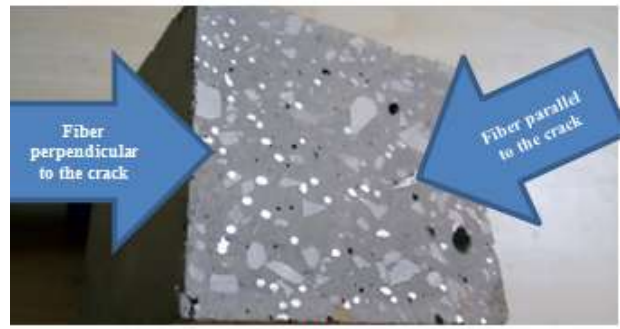

(b)

Plate 1: Visual inspection of fiber a) cutting the specimen b) distribution and orientation of steel fiber. 


\subsection{First Crack Stress and Ductility Index}

Figure 8 shows the results obtained from bending test. It can be noted that the first crack stress increases with more fiber content. It may be attributed to the enhancement of crack initiation resistance resulted by improving the bridging fiber capacity. In addition to that, the first crack stress decreases with mixtures that replace the same percentage of PVA $(0.5 \%)$ by Nylo-mono fiber. The reduction may be due to the value of elastic modulus of Nylomono, which is less than that of PVA. It can be recognized clearly in Figure 9 that the increase of FA in the mixtures results a reduction in the first crack stress. This reduction may be attributed to the fact that the increase of FA causes a lower toughness $[10,11]$.

The stress and ductility indexes were calculated according Equations 3 and 4, respectively. The results indicated that there are no significant effects of increasing FA within the mixtures contain only steel fiber on stress or ductility indexes. On the other hand, there is a rise in stress index and a reduction in ductility index for mixtures utilizing steel fiber and PVA as shown in Figures 10 and 11. In turn, more FA with replacing PVA by Nylo-mono fiber with the same fraction $(0.5 \%)$ stated an increase in stress and ductility indexes. Figure 12 presents the effect of fiber type on the ductility index. The results demonstrate that the utilization of Nylo-mono fiber enhances the ductility index better than those mixtures contain PVA especially when the $(\mathrm{A} / \mathrm{B}=1.5$ and 2$)$ which is similar to the study findings by Banyhussan et al. [10]. The ductility and stress indexes improved with the more FA dosage. It may be adue to the existing of fiber texture, which increases the fractional bond $[12,13]$.

Stress Index $=\frac{\text { postpeak Stress }}{\text { First Crack Stress }}$

Ductility Index $=\frac{\text { Max deflection capacity }}{\text { First crack deflection }}$

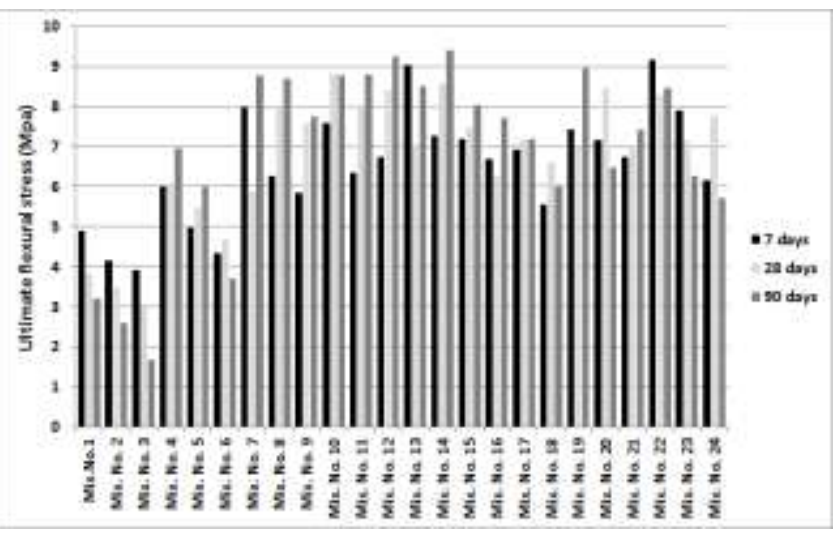

Fig. 4: Maximum stress at different curing ages; 7, 28 and 90 days.

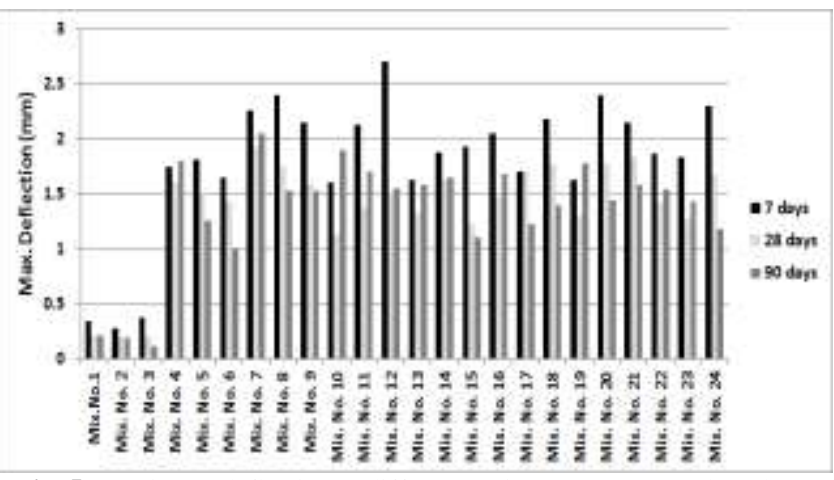

Fig. 5: Maximum deflection at different curing ages; 7, 28 and 90 days.

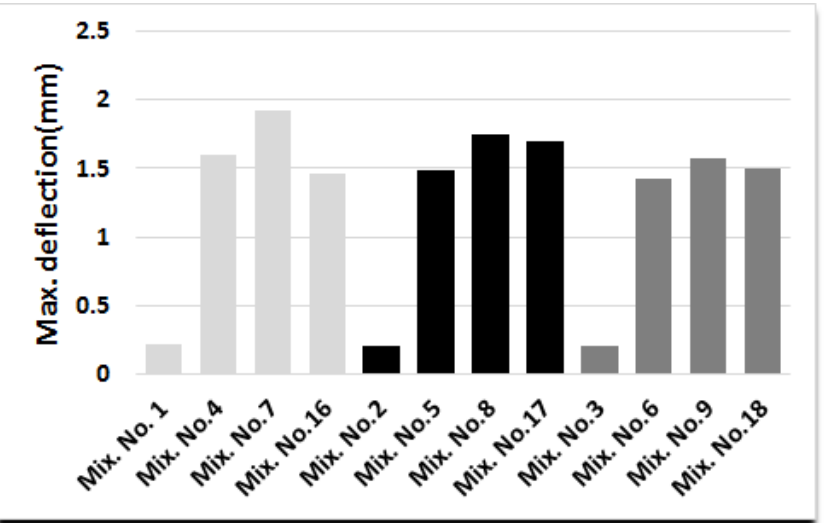

Fig. 6: Effect of fiber addition on the deflection capacity at $(\mathrm{A} / \mathrm{B})=1$.

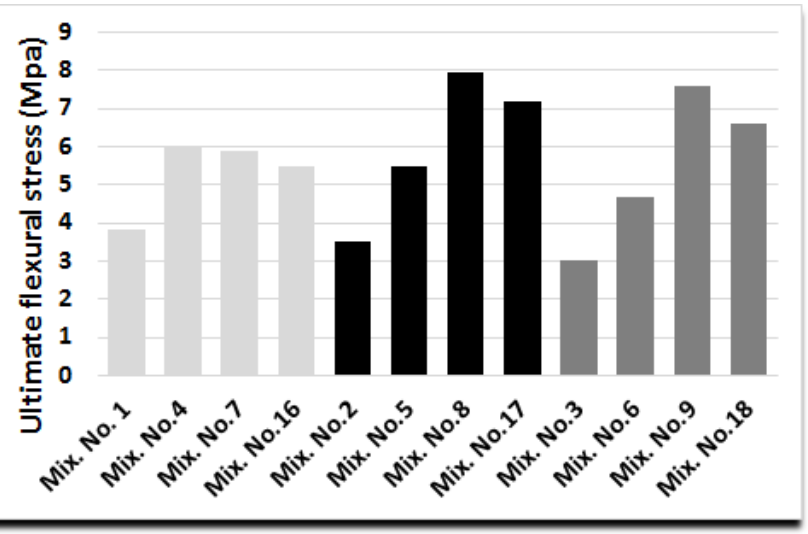

Fig. 7: Effect of fiber addition on the flexural stress with $(\mathrm{A} / \mathrm{B})=1$.

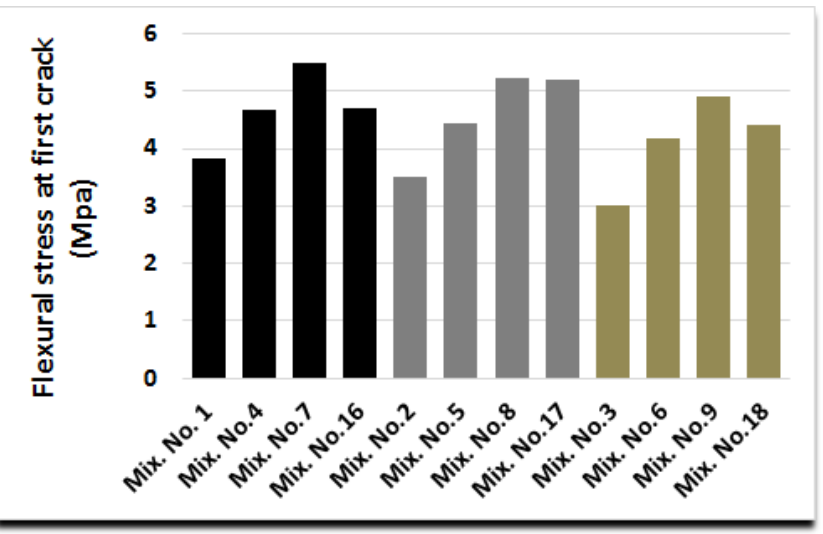

Fig. 8: Effect of addition of fiber on the flexural stress at first crack, $\mathrm{A} / \mathrm{B}=1$

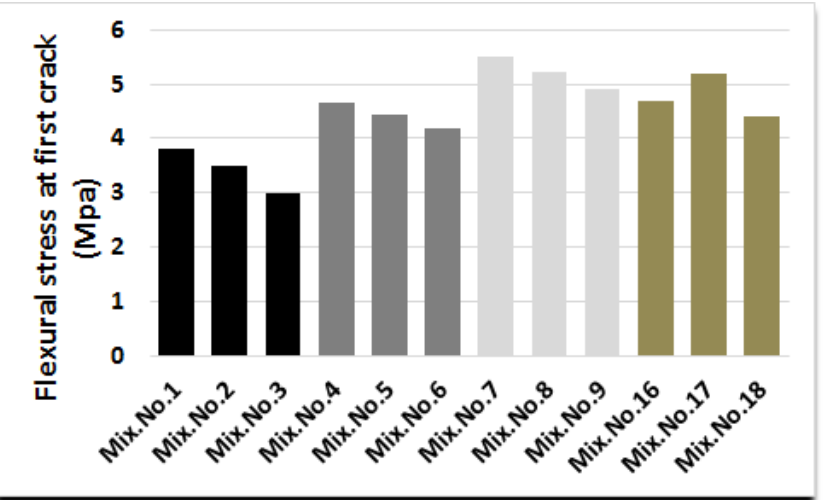

Fig. 9: Effect of Fly ash on the first crack stress $A / B=1$. 


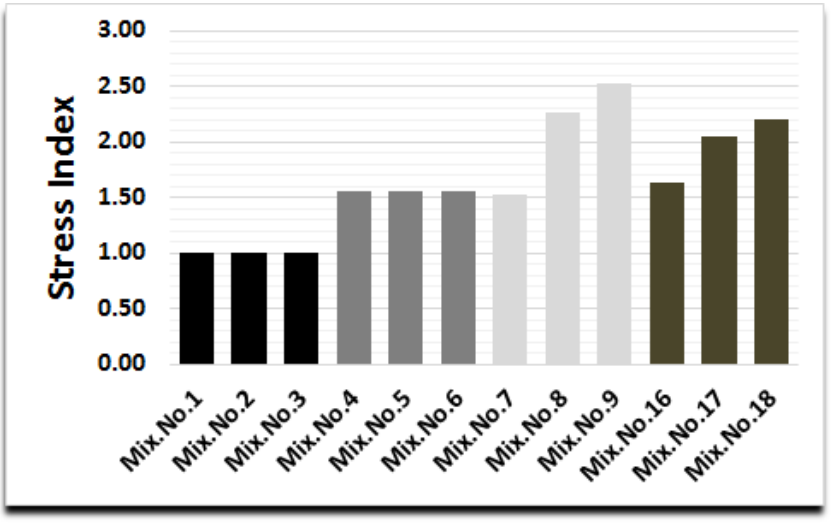

Fig. 10: Effect of (FA) on the Stress Index with (A/B) ratio=1.

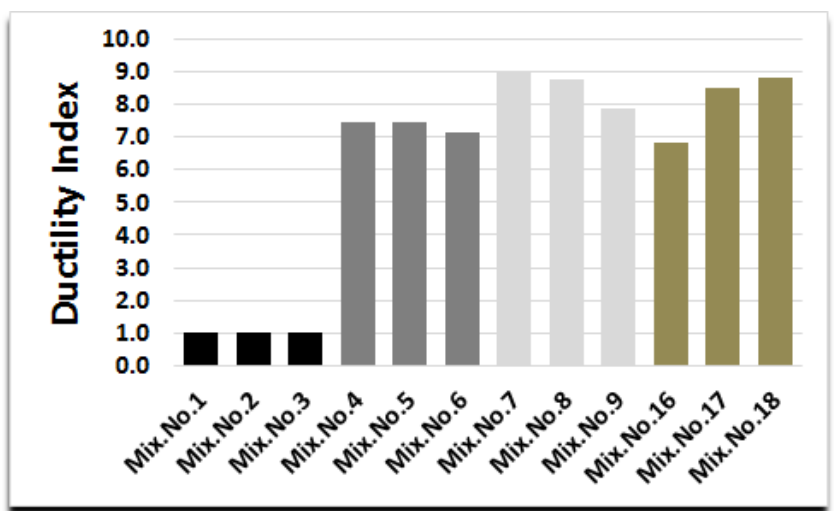

Fig. 11: Effect of (FA) on the Ductility Index with (A/B) ratio $=1$.

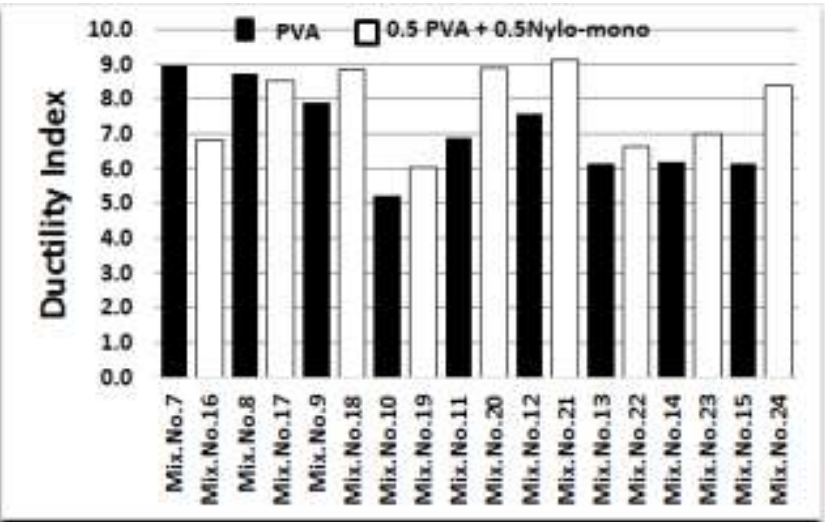

Fig. 12: Effect of replacement of PVA by Nylo-mono fiber on the ductility index.

\section{Conclusions}

In this study, hybrid fiber reinforced concrete was experimentally investigated to develop a ductile concrete. The following conclusions could be drawn from the present investigation.

Mixtures No. 4-6 with total fiber content of only $1 \%$ steel fiber by volume, contributes by increasing post peak flexural strength and deflection capacity.

The first crack stress improved with the increase in fiber content. On the other hand, the first crack stress decreases with mixtures replace PVA by Nylo-mono of the same percentage $(0.5 \%)$.

The results show that the use of Nylo-mono enhances the ductility index better than the corresponding mixtures contain PVA especially when $(\mathrm{A} / \mathrm{B}=1.5$ and 2$)$.

The use of $2 \%$ by volume hybrid fiber (PVA0.5+Steel.0\%+Nylomono 0.5 ) achieved a ductile concrete mixture that has a ductility index nine times higher than that of plain concrete.

\section{References}

[1] Afroughsabet, V, \& Ozbakkaloglu T. (2015), Mechanical and durability properties of high-strength concrete containing steel and polypropylene fibers. Construction and building materials, 94, 73-82.

[2] Pająk M, \& Ponikiewski, T. (2013), Flexural behavior of selfcompacting concrete reinforced with different types of steel fibers. Construction and Building Materials, 47, 397-408.

[3] Yun H D, Yang I S, Kim S W, Jeon E, Choi C S, \& Fukuyama H. (2007), Mechanical properties of high-performance hybrid-fibrereinforced cementitious composites (HPHFRCCs). Magazine of Concrete Research, 59(4), 257-271.

[4] Yang E \& Li V C. (2006), Rate dependence in engineered cementitious composites. In International RILEM workshop on high performance fiber reinforced cementitious composites in structural applications (pp. 83-92). RILEM Publications SARL.

[5] Huntzinger D N, \& Eatmon T D. (2009), A life-cycle assessment of Portland cement manufacturing: comparing the traditional process with alternative technologies. Journal of Cleaner Production, 17(7), 668-675.

[6] Colin D J. (2001), Fiber-Reinfiorced Cements and Concretes Advances in concrete technology -Volume-3, Gordon and Breach Science publishes.

[7] Berry E E, Hemmings, R T, Zhang M H, \& Malhotra V M. (1992), Fourth international conference on fly ash, silica fume, slag, and natural pozzolans in concrete: Supplemental proceedings (No. EPRI-TR--100577). Electric Power Research Inst..

[8] Koksal F, Gencel O \& Kaya M. (2015), Combined effect of silica fume and expanded vermiculite on properties of lightweight mortars at ambient and elevated temperatures. Construction and Building Materials, 88, 175-187.

[9] Wang, Shuxin \& Victor C L. (2007), Engineered cementitious composites with high-volume fly ash. Materials Journal 104.3: 233241.

[10] Banyhussan QS, Gürkan Y, Ender B, Serhat D, and Sahmaran M. (2016), Deflection-hardening hybrid fiber reinforced concrete: The effect of aggregate content. Construction and Building Materials 125: 41-52.

[11] Al-Dahawi AM (2018), Effect of curing age on the self-sensing behavior of carbon-based engineered cementitious composites (ECC) under monotonic flexural loading scenario, MATEC Web of Conferences, 162, 01034.

[12] Sahmaran M, Christianto H A, \& Yaman İ Ö. (2006), The effect of chemical admixtures and mineral additives on the properties of selfcompacting mortars. Cement and concrete composites, 28(5), 432440.

[13] Ramseyer C C, \& Kiamanesh R (2009), Optimizing concrete mix designs to produce cost effective paving mixes(No. FHWA-OK-0811). Civil Engineering and Environmental Science, University of Oklahoma. 